\title{
Erratum: "Determination of the Negative Hydrogen Ion Concentration in a Cesium-Hydrogen Discharge" [Technical Physics 46 (8), 946 (2001)]
}

F. G. Baksht, V. G. Ivanov, S. I. Kon'kov, and S. M. Shkol'nik

Wrong values were indicated on the $y$-axis of Fig. $4 \mathrm{~b}$ (page 949.) The correct version of this figure is given below.

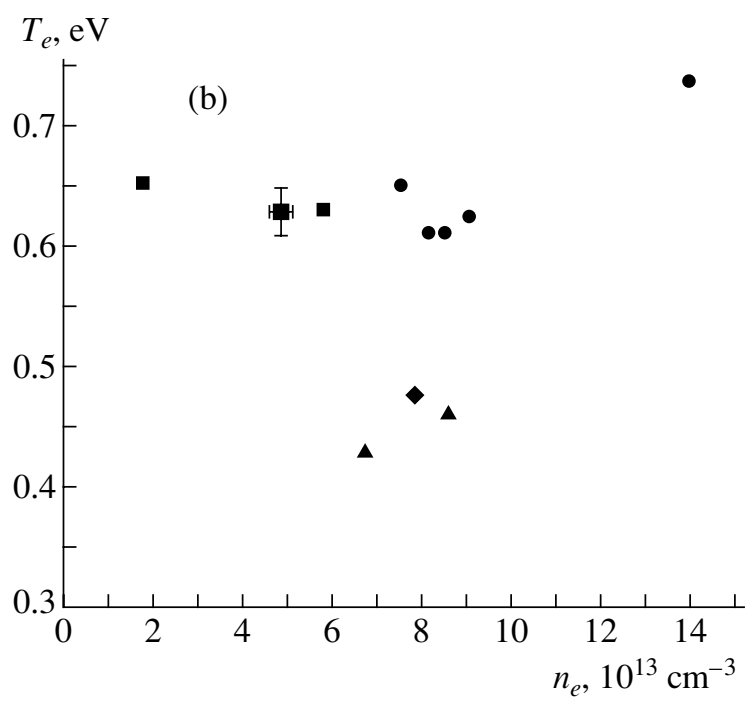

